\title{
Validating TDP1 as an Inhibition Target for the Development of Chemosensitizers for Camptothecin-Based Chemotherapy Drugs
}

\author{
Euphemia Leung (D) - Jinal Patel • Jennifer A. Hollywood (D) - Ayesha Zafar (D) - Petr Tomek (D) • \\ David Barker (D) - Lisa I. Pilkington (D) - Michelle van Rensburg • Ries J. Langley (D) • \\ Nuala A. Helsby (D) · Christopher J. Squire (D) · Bruce C. Baguley (D) - William A. Denny (D) \\ Jóhannes Reynisson (D) - Ivanhoe K. H. Leung (D)
}

Received: May 7, 2021 / Accepted: June 3, 2021 / Published online: June 23, 2021

(C) The Author(s) 2021

\begin{abstract}
Cancer chemotherapy sensitizers hold the key to maximizing the potential of standard anticancer treatments. We have a long-standing interest in developing and validating inhibitors of the DNA repair enzyme tyrosyl-DNA phosphodiesterase 1 (TDP1) as chemosensitizers for topoisomerase I poisons such as topotecan.
\end{abstract}

Euphemia Leung and Jinal Patel contributed equally to this work.

Supplementary Information The online version contains supplementary material available at https:// doi.org/10.1007/s40487-021-00158-0.

E. Leung $(\bowtie) \cdot$ P. Tomek · B. C. Baguley ·

W. A. Denny

Auckland Cancer Society Research Centre, School of Medical Sciences, The University of Auckland, Private Bag 92019, Victoria Street West, Auckland 1142, New Zealand

e-mail: e.leung@auckland.ac.nz

E. Leung · J. A. Hollywood · R. J. Langley ·

N. A. Helsby

Department of Molecular Medicine and Pathology, School of Medical Sciences, The University of Auckland, Private Bag 92019, Victoria Street West, Auckland 1142, New Zealand

E. Leung · R. J. Langley · C. J. Squire .

I. K. H. Leung $(\square)$

Maurice Wilkins Centre for Molecular Biodiscovery,

The University of Auckland, Private Bag 92019,

Victoria Street West, Auckland 1142, New Zealand
Herein, by using thieno[2,3- $b]$ pyridines, a class of TDP1 inhibitors, we showed that the inhibition of TDP1 can restore sensitivity to topotecan, results that are supported by TDP1 knockout cell experiments using CRISPR/Cas9. However, we also found that the restored sensitivity towards topoisomerase I inhibitors is likely regulated by multiple complementary DNA repair pathways. Our results showed that one of these pathways is likely modulated by PARP1, although it is also possible that other redundant and partially overlapping pathways may be involved in the DNA repair process. Our work thus raises the prospect of targeting

J. Patel · A. Zafar · D. Barker · L. I. Pilkington · M. van Rensburg · J. Reynisson ( $₫)$. I. K. H. Leung School of Chemical Sciences, The University of Auckland, Private Bag 92019, Victoria Street West, Auckland 1142, New Zealand

D. Barker

The MacDiarmid Institute for Advanced Materials and Nanotechnology, Victoria University of Wellington, PO Box 600, Wellington 6140, New Zealand

C. J. Squire

School of Biological Sciences, The University of Auckland, Private Bag 92019, Victoria Street West, Auckland 1142, New Zealand

J. Reynisson

School of Pharmacy and Bioengineering, Keele

University, Staffordshire ST5 5BG, UK

e-mail: j.reynisson@keele.ac.uk 
multiple DNA repair pathways to increase the sensitivity to topoisomerase I inhibitors.

Keywords: DNA repair; TDP1; Thieno[2,3b]pyridines; Topotecan; Topoisomerase I

\section{Key Summary Points}

Why carry out this study?

Side effects and the development of chemoresistance are unresolved challenges in cancer chemotherapy.

Chemosensitizers may help solve these issues by making cancer cells more vulnerable to conventional chemotherapy drugs.

Our work aims to validate the DNA repair enzyme tyrosyl-DNA phosphodiesterase 1 (TDP1) as an inhibition target for the development of chemosensitizers for camptothecin-based chemotherapy drugs such as topotecan.

\section{What was learned from the study?}

Inhibition of TDP1 may restore sensitivity to topotecan.

TDP1 inhibitors also induced a potentiation effect in TDP1 knockout cells, indicating that multiple complementary DNA repair pathways may exist to repair the DNA damage caused by topotecan.

Our results highlight the prospect of targeting multiple DNA repair pathways to increase the sensitivity to topoisomerase I inhibitors.

\footnotetext{
I. K. H. Leung

School of Chemistry, The University of Melbourne, Parkville, VIC 3010, Australia

e-mail: ivanhoe.leung@unimelb.edu.au

I. K. H. Leung

Bio21 Molecular Science and Biotechnology

Institute, The University of Melbourne, Parkville,

VIC 3010, Australia
}

\section{DIGITAL FEATURES}

This article is published with digital features, including a summary slide, to facilitate understanding of the article. To view digital features for this article go tohttps://doi.org/10.6084/m9. figshare.14725317.

\section{INTRODUCTION}

Although chemotherapy is now routinely applied to treat cancer patients, the unpleasant (and sometimes severe) side effects and the eventual development of chemoresistance remain unresolved challenges. In order to mitigate these issues, the use of chemosensitizers to enhance the efficacy of chemotherapy has been a focus of intense research in the last two decades $[1,2]$. Chemosensitizers make cancer cells more vulnerable to conventional chemotherapy drugs, allowing lower dosages to be used $[1,2]$. Hence, chemosensitizers hold the potential to delay or reverse chemoresistance, reduce dosage-related toxicity and minimize side effects.

Topotecan and irinotecan are among the Food and Drug Administration (FDA)-approved chemotherapy drugs that are structurally based on camptothecins [3-5]. Camptothecins are pentacyclic quinoline alkaloids that target DNA topoisomerase I, a DNA-cleaving enzyme that plays a key role in relaxing tangled DNA during its replication and transcription [6, 7]. Camptothecins inhibit topoisomerase I by trapping the covalent topoisomerase I-DNA complex, which in turn interferes with the cellular replicative and transcriptional machinery $[8,9]$. This causes DNA damage and potent cytotoxicity, which is utilized to kill rapidly dividing cancer cells. However, the cytotoxicity of camptothecins is limited by intrinsic cancer cell resistance, which is thought to be mediated by DNA repair pathways [10-12]. One of these DNA pathways is modulated by the enzyme tyrosyl-DNA phosphodiesterase 1 (TDP1) [13-15]. TDP1 releases stalled topoisomerase I-DNA cleavage complexes by catalyzing the hydrolysis of the phosphodiester bond between the catalytic tyrosine residue of topoisomerase I 
and the phosphate group of DNA [13-15]. The activity of TDP1 and topoisomerase I in tumor cells is positively correlated [16]. There is evidence that TDP1 expression may lessen the cytotoxicity of camptothecin-based drugs [17]. Preclinical data have also shown that the level of TDP1 activity may influence cellular sensitivity to camptothecin-based drugs and other topoisomerase I inhibitors [18, 19].

Our laboratories have a long-standing interest in the development and validation of sensitizers for camptothecin-based chemotherapy drugs [20-38]. Specifically, our recent work indicated that TDP1 inhibitors may potentiate topotecan both in vitro and in vivo [31]. Although this study provides an impetus for the development of selective TDP1 inhibitors as camptothecin sensitizers, the presence of multiple DNA repair pathways and enzymes other than TDP1 may present an obstacle to this drug development prospect [39-43]. Thus, it is important to illuminate the association between TDP1 activity and camptothecin sensitivity. Our previous work showed that compounds containing the thieno[2,3- $b]$ pyridine scaffold are inhibitors of TDP1 [35, 38], and thus represent excellent model compounds for the investigation. We therefore set out to study the modulation of TDP1 activity with thieno[2,3-b]pyridines to potentiate the effects of topotecan.

\section{METHODS}

\section{Chemicals and Reagents}

Unless otherwise stated, all chemicals were obtained from Sigma-Aldrich, Merck, Life Technologies, Bio-Rad, Abcam and AK Scientific. Topotecan and olaparib were purchased from Sigma-Aldrich.

\section{Cell Culture}

Culture conditions have been described in detail previously [44, 45]; Hs578T, BT549, MDAMB-231, SKBR3, MCF7, T47D, BT474, MDA-MB453, MDA-MB-436, A172, SUM149T, HCF116,
MiaPaCa, PANC1, A549, HeLa and H460 cancer cell lines were purchased from the American Type Culture Collection (ATCC). SUM149PT and SUM150PT were grown in Ham's F-12 with $5 \%$ fetal calf serum (FCS) supplemented with $5 \mu \mathrm{g} / \mathrm{mL}$ insulin, $1 \mu \mathrm{g} / \mathrm{mL}$ hydrocortisone, $10 \mathrm{mM}$ 4-(2-hydroxyethyl)-1-piperazineethanesulfonic acid (HEPES; pH 7.4) and penicillin/ streptomycin $(100 \mathrm{U} / \mathrm{mL}$ and $100 \mu \mathrm{g} / \mathrm{mL}$, respectively). All other cells were grown in $\alpha$ MEM containing 5\% fetal bovine serum (FBS), insulin/transferrin/selenium supplement, added according to the manufacturer's instructions (Roche), and penicillin/streptomycin (100 $\mathrm{U} / \mathrm{mL}$ and $100 \mu \mathrm{g} / \mathrm{mL}$, respectively). Ethics committee approval was not required for the handling of commercial cell lines.

\section{Cell Proliferation Assay}

As described in detail previously [44], proliferation was measured using a thymidine incorporation assay. A total of 3000 cells were seeded in 96-well plates in the presence of varying concentrations of inhibitors for 3 days. ${ }^{3} \mathrm{H}$-thymidine was added to each well and incubated for $6 \mathrm{~h}$; the cells were harvested on glass fiber filters using an automated Tomtec harvester. Filters were incubated with Betaplate Scint and thymidine incorporation measured in a TriLux/ Betaplate counter. The effects of the inhibitors were determined relative to the incorporation of ${ }^{3} \mathrm{H}$-thymidine into DNA of control (nondrug-treated) cells.

\section{Guide Ribonucleic Acid (gRNA) Design and Cloning}

Optimal gRNA [46] with forward and reverse oligos 5'-CACC GACATCTCTGCTCCCAATGA$3^{\prime}$ and 5'-AAAC TCATTGGGAGCAGAGATGTC$3^{\prime}$ were ligated and cloned into the pSpCas9 (BB)-2A-GFP (PX458) vector by Golden Gate cloning [47]; pSpCas9(BB)-2A-GFP (PX458) was a gift from Feng Zhang (Addgene plasmid \# 48138; $\quad$ http://n2t.net/addgene:48138; RRID:Addgene_48138). Cells were transfected by Lipofectamine 3000, and GFP-positive cells were isolated $48 \mathrm{~h}$ later by flow cytometric 
sorting and seeded as single cells. Knockout clones were confirmed by PCR amplification of the targeted exon followed by sequence analysis (see Supporting Information, Figure S1) to confirm disruption of coding sequences at the targeted site. Cells are referred to as MCF7 TDP1_KO_2.8 and H460 TDP1_KO_1.3. Ethics committee approval was not required for the mutation of the cell lines.

\section{Western Blotting}

As described in detail previously [44], breast cancer cell lines were grown to log-phase, washed twice with ice-cold PBS, and lysed in SDS lysis buffer according to the manufacturer's protocol (Cell Signaling Technology, Danvers, MA, USA). Protein concentration was quantified using the bicinchoninic acid reagent (Sigma). Cell lysates containing $25 \mu \mathrm{g}$ of protein were separated by SDS-polyacrylamide gel electrophoresis (PAGE) and transferred to PVDF membranes (Millipore). Membranes were subjected to immunoblotting with antibodies against TDP1 (Abcam AB4166), PARP1 (Cell Signaling Technology \#9542), and tubulin (Sigma). Bound antibody was visualized using the Pierce ECL Western Blotting Substrate (Thermo Fisher Scientific) and chemiluminescence detection by the ChemiDoc imaging system (Bio-Rad).

\section{Flow Cytometric Analysis}

Cells $\left(5 \times 10^{5}\right.$ cells for MCF7 or $5 \times 10^{5}$ cells for $\mathrm{H} 460$ per well) were grown in 6-well plates overnight. After $24 \mathrm{~h}$, cells were incubated for $2 \mathrm{~h}$ with inhibitors. The concentration used for DJ009 was $5 \mu \mathrm{M}$, and the topotecan concentration was $0.5 \mu \mathrm{M}$ for MCF7 or $1 \mu \mathrm{M}$ for H460. Cells were harvested, washed and resuspended in $1 \mathrm{~mL}$ of blocking buffer (1\% FCS/PBS), and incubated with antibody to $\gamma$-H2AX (phosphorylated Ser139) (Millipore, USA) in blocking buffer (1:500 dilution) at room temperature for $2 \mathrm{~h}$. Cells were washed, incubated with goat anti-mouse Alex 488 Fab fragment secondary antibody (Invitrogen) (1:400 in blocking buffer for $1 \mathrm{~h}$, at room temperature; dark), washed and resuspended in $1 \mathrm{~mL}$ of blocking buffer containing RNase $(1 \mu \mathrm{g} / \mathrm{mL})$ and propidium iodide (PI) $(10 \mu \mathrm{g} / \mathrm{mL})$ for $30 \mathrm{~min}$ at room temperature. Cells were analyzed in a Becton Dickinson BD Accuri C6 flow cytometer.

\section{Data analysis}

The Bliss additivism model [48] was used to classify the effect of combining topotecan and other inhibitors as additive, synergistic, or antagonistic. A theoretical curve was calculated for combined inhibition using the equation $E_{\text {bliss }}=E \mathrm{~A}+E \mathrm{~B}-E \mathrm{~A} \times E \mathrm{~B}$, where $E \mathrm{~A}$ and $E \mathrm{~B}$ are the fractional inhibitions obtained by drug A alone and drug $B$ alone at specific concentrations. $E_{\mathrm{bliss}}$ is the fractional inhibition that would be expected if the combination of the two drugs was exactly additive. The differences (Bliss) in the experimentally measured fractional inhibition $\left(E_{\mathrm{xpt}}\right)$ and $E_{\text {bliss }}$ are defined as synergism $\left(E_{\mathrm{xpt}}<E_{\text {bliss }}\right)$, additivity $\left(E_{\mathrm{xpt}}=E_{\text {bliss }}\right)$, and antagonism $\left(E_{\mathrm{xpt}}>E_{\mathrm{bliss}}\right)$. Bliss $=0$ would indicate the combination is additive; Bliss $>0$ would indicate the percentage increase in maximal inhibition above additivity (synergy); and Bliss $<0$ would indicate the percentage decrease in maximal inhibition below additivity (antagonism).

\section{TDP1 Biosensor Assay}

The recombinant TDP1 was purified as described below. The TDP1-biosensor 5'-(5,6 FAM-aac gtc agg gtc ttc c-BHQ1)-3' was purchased from Integrated DNA Technologies; 5,6 FAM is fluorophore 5(6)-carboxyfluorescein, and BHQ1 is fluorescence quencher Black Hole Quencher 1. As described in detail previously [31], the TDP1biosensor, with a final concentration of $50 \mathrm{nM}$, was incubated in a volume of $200 \mu \mathrm{L}$ containing a TDP1 buffer (50 mM Tris- $\mathrm{HCl} \mathrm{pH} 8.0,50 \mathrm{mM}$ $\mathrm{NaCl}, 7 \mathrm{mM} \beta$-mercaptoethanol) supplemented with a purified $3 \mathrm{nM}$ TDP1. The reaction mixtures were incubated at a constant temperature of $24^{\circ} \mathrm{C}$ in an EnSpire 2300 Multimode Plate Reader (PerkinElmer, Singapore) to measure fluorescence every $1 \mathrm{~min}$ (Ex485/Em520 nm). 
The relative TDP1 activity was measured at 7 min compared to that of DMSO control wells.

\section{Molecular Modeling}

The compounds were docked against the crystal structure of TDP1 (PDB ID: 6DIE, resolution $1.78 \AA$ ) [49] which was obtained from the Protein Data Bank (PDB) [50, 51]. The Scigress version FJ 2.6 program [52] was used to prepare the crystal structure for docking, i.e., the hydrogen atoms were added, the co-crystallised ligand benzene-1,2,4-tricarboxylic acid was removed as well as crystallographic water molecules except $\mathrm{HOH} 814,821$ and 1078. The water molecules were set on toggle-bound or displaced by the ligand during docking, and spin-automatic optimization of the orientation of the hydrogen atoms. The Scigress software suite was also used to build the inhibitors, and the MM2 force field [53] was applied to identify the global minimum using the CONFLEX method [54] followed by structural optimization. The docking center was defined as the position of a carbon on the ring of the co-crystallized benzene-1,2,4-tricarboxylic acid $(x=-6.052, \quad y=-14.428, \quad z=33.998)$ with $10 \AA$ radius. Fifty docking runs were allowed for each ligand with default search efficiency (100\%). The basic amino acids lysine and arginine were defined as protonated. Furthermore, aspartic and glutamic acids were assumed to be deprotonated. The GoldScore (GS) [55] and ChemScore (CS) $[56,57]$ ChemPLP (Piecewise Linear Potential) [58] and ASP (Astex Statistical Potential) [59] scoring functions were implemented to predict the binding modes and relative energies of the ligands using the GOLD v5.4.1 software suite.

\section{Recombinant TDP1 Production and Purification}

Synthetic DNA encoding human TDP1 (residues 149-608) [14] was cloned into pET-28a(+) (GenScript), which was then transformed into Escherichia coli BL21(DE3) for recombinant protein production. Protein production was induced with $1 \mathrm{mM}$ isopropyl B-D-1- thiogalactopyranoside (IPTG) at $28^{\circ} \mathrm{C}$ with overnight incubation. TDP1 was purified using affinity and size exclusion chromatography. The purified protein was aliquoted and stored at $-80^{\circ} \mathrm{C}$ until use.

\section{Intrinsic protein fluorescence}

Fluorescence was measured using a PerkinElmer EnSpire Multimode Reader. The TDP1 concentration was $10 \mu \mathrm{M}$ and compound concentrations were $50 \mu \mathrm{M}, 100 \mu \mathrm{M}, 200 \mu \mathrm{M}, 400 \mu \mathrm{M}$, $600 \mu \mathrm{M}$ and $800 \mu \mathrm{M}$. The buffer was composed of $20 \mathrm{mM}$ Tris and $250 \mathrm{mM} \mathrm{NaCl}(\mathrm{pH} \mathrm{8})$. The excitation wavelength was $280 \mathrm{~nm}$ and the intrinsic fluorescence was measured at $350 \mathrm{~nm}$. Control experiments with TDP1 or compound on its own were also conducted. Background fluorescence arising from the compounds was subtracted from the final spectrum. The total volume per well was $30 \mu \mathrm{L}$. Dissociation constants $\left(K_{\mathrm{D}}\right)$ were calculated using the following formula, which takes nonspecific binding into account [60].

$$
I=\frac{I_{\max } \times\left[L_{T}\right]}{K_{\mathrm{D}}+\left[L_{T}\right]}+N_{\mathrm{S}}\left[L_{T}\right]
$$

where $I$ indicates changes in fluorescence intensity from the titration, $I_{\max }$ indicates the maximum fluorescence intensity change, $\left[L_{T}\right]$ is the titration ligand concentration, and $N_{\mathrm{s}}$ is the nonspecific term. Nonlinear curve fitting was conducted using SigmaPlot 13.0 (Systat Software, San Jose, CA, USA). Experiments were conducted in triplicate, and the errors shown are standard deviation.

\section{X-Ray Crystallography}

\section{Crystallization}

Crystallography screening was performed in crystallization plates in a 96-well format. The highly purified human TDP1 148 -608 was bufferexchanged into a buffer containing $50 \mathrm{mM} 4$-(2hydroxyethyl)-1-piperazineethanesulfonic acid (HEPES) and $50 \mathrm{mM} \mathrm{NaCl}$ at pH 7.8 and was then concentrated to $6.5 \mathrm{mg} / \mathrm{mL}$. After 6-8 days of incubation at $18{ }^{\circ} \mathrm{C}$, the formation of large 
needle-shaped crystals was observed in the finescreened liquid containing $200 \mathrm{mM}$ ammonium chloride, $100 \mathrm{mM}$ HEPES, pH 7 and 20\% PEG 6000 . The crystals were supplemented with $20 \%$ glycerol and then flash-frozen in liquid nitrogen for data collection.

\section{Data Collection and Processing}

The data for TDP1 $1_{148-608}$ were collected remotely at the School of Biological Sciences, The University of Auckland, using the Australian Synchrotron MX2 beamline. The data were collected using MX2 beamline with the help of Blu-Ice software with a resolution of $2.13 \AA$ [61]. The TDP1 $1_{149-608}$ data were indexed and integrated using the autoprocessing software XDS [62]. The data were scaled using the AIMLESS software package [63].

\section{Crystallographic Refinement}

The structure was solved by molecular replacement using the PHASER MR program [64] using the available published crystal structure from the PDB [65]. The structure was solved in P212121, which is expected as per published PDB (1JY1) (detail numbers are described in Supporting Information, Table S1). The final structure was then refined using the REFMAC software package [66], and coordinates and electron density were observed using COOT modeling software [67]. The water molecules were identified by their spherical electron density and appropriate hydrogen bond geometry with the surrounding structure. The preliminary coordinates were visualized, and figures were produced using Pymol [68].

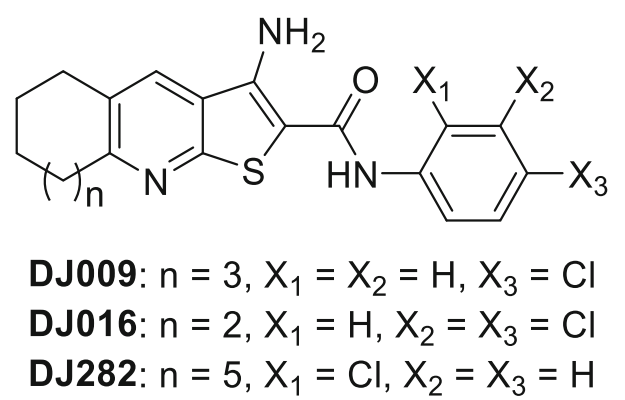

Fig. 1 Structures of DJ009, DJ016 and DJ282

\section{RESULTS}

As our initial work with thieno[2,3-b]pyridines and TDP1 was conducted with a relatively small library [35, 38], we first carried out in vitro studies to validate thieno[2,3- $b$ ]pyridines as inhibitors of TDP1. One of our laboratories has synthesized and acquired $>100$ thieno[2,3b]pyridines derivatives [35, 38, 69-77]. By using this extensive library, we screened for inhibition of TDP1 activity using a fluorescence-based inhibition assay with a synthetic oligonucleotide biosensor as substrate [78]. At $25 \mu \mathrm{M}$ ligand concentration, $28(22 \%)$ out of the 128 derivatives showed $>50 \%$ TDP1 inhibition (see Supporting Information, Figure S2). For the purpose of this study, three of the 28 compounds were chosen for further evaluations (DJ009, DJ016 and DJ282; Fig. 1). They were chosen because of their strong inhibitory effect in the biosensor assay and low antiproliferative activity at $500 \mathrm{nM}$. Binding studies using intrinsic fluorescence spectroscopy showed that these three compounds bind to TDP1 with affinity in the micromolar range (see Supporting Information, Figures S3-S5). In agreement with previous studies [35, 38], molecular modeling showed that these three compounds have a plausible binding conformation in the active site (see Supporting Information, Figures S6-S8 and Table S2). Protein X-ray crystallography was also attempted. However, despite numerous attempts using both the soaking and co-crystallization methods, we were only able to obtain the structure of apo-TDP1, which is almost identical to the published TDP1 structure (see Supporting Information Figure S9 and Table S1) [65].

Having confirmed that thieno[2,3- $b]$ pyridines inhibit TDP1 in vitro, we set out to examine the synergistic effects of thieno[2,3-b]pyridines and topotecan on the proliferation of cancer cell lines. DJ009 was used against a panel of 16 cancer cell lines as an initial screen. These cell lines were chosen to reflect the cancers that topotecan is currently used to treat in the clinic, as well as a number of other cell lines to evaluate whether TDP1 inhibitors could broaden the spectrum of cancers that could be targeted 

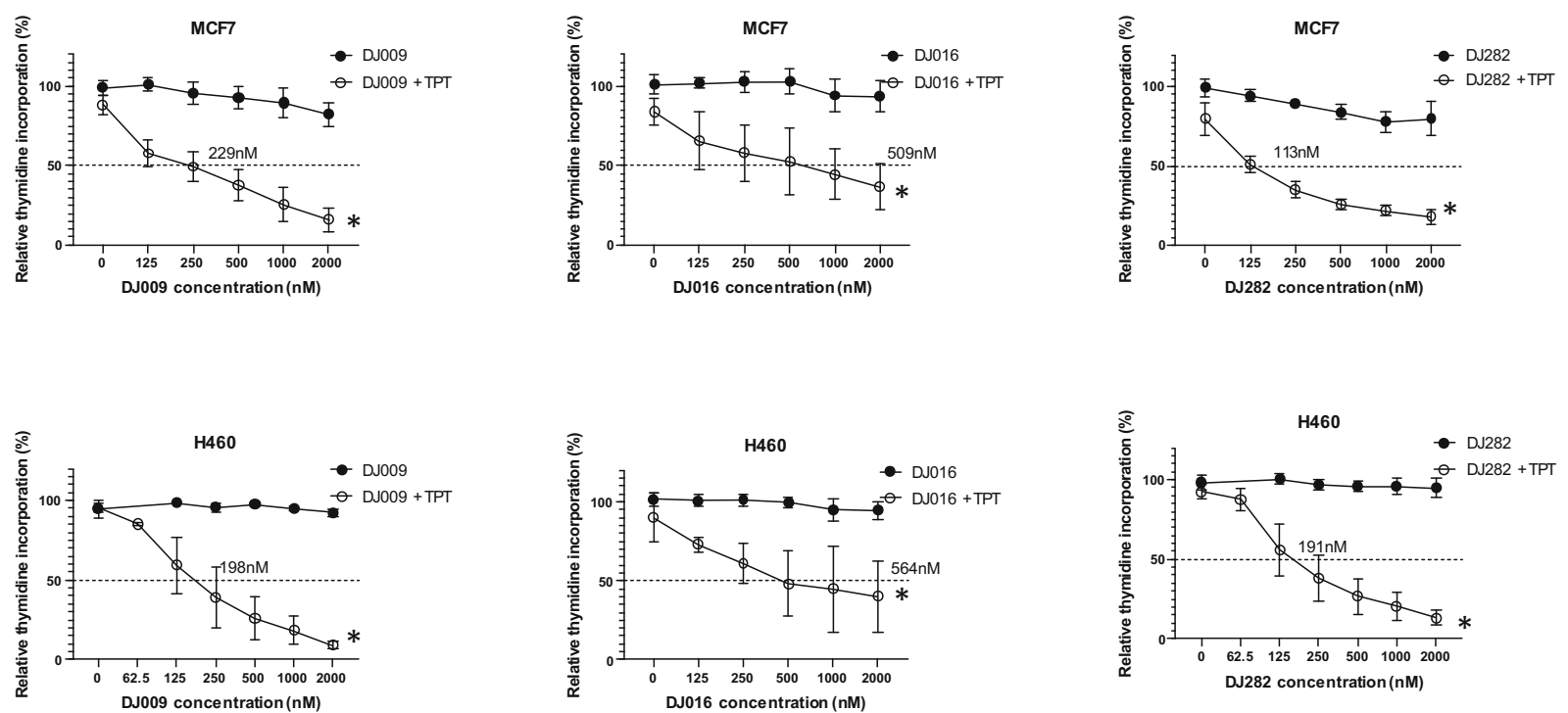

Fig. 2 The potentiating effect of DJ009, DJ016 and DJ282 with topotecan (abbreviated as TPT in the figure). The topotecan concentration is $12.5 \mathrm{nM}$ for MCF7 and $25 \mathrm{nM}$ for $\mathrm{H} 460$. IC $\mathrm{IC}_{50}$ values for the combination treatments (by identification of the $50 \%$ value, dashed line) are shown on each graph. Data are mean \pm SE of three independent experiments. DJ009 showed the strongest synergistic effect as calculated using the Bliss additivism model [48]. The average Bliss value (where Bliss $>1$, indicates synergy) for the combination of the

by topotecan. The $\mathrm{IC}_{50}$ (concentration that reduces cell proliferation by 50\%) values of topotecan alone or in combination with DJ009 were determined using thymidine incorporation assay after $72 \mathrm{~h}$ of drug exposure. Interestingly, sensitivity to topotecan varied between the cell lines. At $500 \mathrm{nM}$, DJ009 significantly sensitized the inhibitory effect of topotecan in the MCF7 breast cancer cell line, as well as the lung cancer cell lines A549 and H460 (Fig. 2, and see Supporting Information, Figure S10). Similarly, DJ016 and DJ282 showed a synergistic effect to topotecan when tested against MCF7 and H460 cells (Fig. 2). As control, DJ009, DJ016 or DJ282 on their own at $1 \mu \mathrm{M}$ concentration had no or little effect on the proliferation of the cancer cell lines (Fig. 2), indicating that the inhibition observed in the combination experiments was likely due to topotecan. To further verify that topotecan is the compound that reduces the observed growth, we tested for thieno[2,3-b]pyridine compounds and topotecan were $44.2 \pm 11.4, \quad 31.8 \pm 8.1$ and $37.4 \pm 8.0$ for DJ009, DJ016, and DJ282, respectively in MCF7 cells. The combined treatment for $\mathrm{H} 460$ cells also showed a synergistic effect with Bliss values of $60.9 \pm 17.8$, $31.1 \pm 8.9$ and $58.6 \pm 14.8$ for DJ009, DJ016 and DJ282, respectively. These results clearly demonstrate a strong synergistic effect between the three thieno[2,3b]pyridines and topotecan

DNA damage in H460 and MCF7 cells by measuring $\gamma$-phosphorylation of the histone H2AX, which is a marker for DNA damage (see Supporting Information, Figure S11) [79]. A comparison of flow cytometry profiles following treatment for $2 \mathrm{~h}$ showed an S-phase-specific DNA damage profile with a significant $\gamma$-H2AX increase in combination treatment with DJ009 and topotecan compared with topotecan alone (see Supporting Information, Figure S11). As control, DJ009 induced no DNA damage response (see Supporting Information, Figure S11). This result showed that the growth inhibitory effect and increased DNA damage are likely due to impaired DNA repair mechanisms in H460 and MCF7 cells, consistent with our hypothesis that the thieno[2,3-b]pyridines act as potentiators of topotecan.

To confirm the involvement of TDP1 blockade in potentiating topotecan, we used CRISPR/ Cas9 (clustered regularly interspaced short 


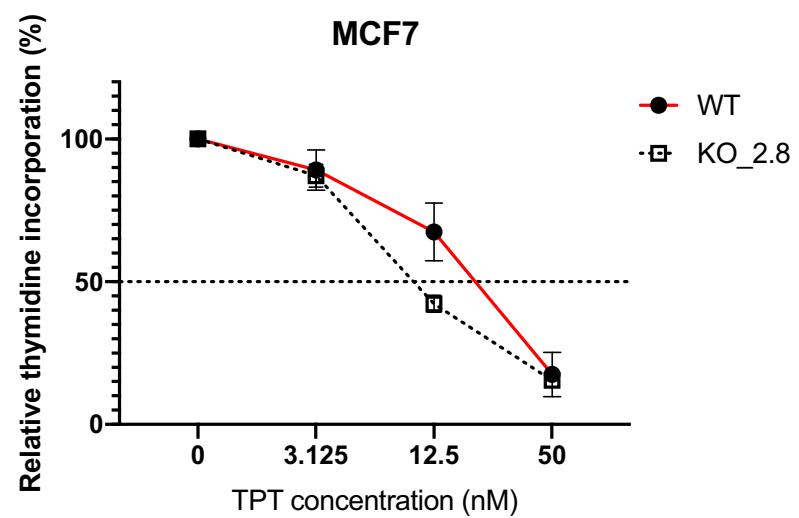

Fig. 3 The effect of TDP1 KO on the antiproliferative activity of topotecan (abbreviated as TPT in figure axis) as compared to WT cells. TDP1 KO increases the sensitivity

palindromic repeats/CRISPR associated protein 9) to knock out TDP1. We introduced frameshift mutations in the TDP1 coding sequence using gRNAs against TDP1 to generate TDP1 knockout (KO) clones in MCF7 and H460 cancer cells. Frameshift mutations in knockout cell lines were validated by Sanger sequencing, and complete TDP1 ablation was verified by immunoblotting (see Supporting Information, Figure S12). We then tested the sensitivity of topotecan in the TDP1 KO clones (MCF7 KO_2.8 and H460 KO_1.3) and compared our results with the wild-type cells (MCF7 and H460). Our results showed that TDP1-deficient H460 and MCF7 cells proliferated less when exposed to topotecan (Fig. 3). The $\mathrm{IC}_{50}$ values for topotecan were $25.2 \pm 1.6 \mathrm{nM}$ in wild-type MCF7 cells and $10.5 \pm 1.1 \mu \mathrm{M}$ in TDP1 KO_2.8 MCF7 cells. Similarly, the $\mathrm{IC}_{50}$ values for topotecan were $32.4 \pm 1.8 \mathrm{nM}$ in TDP1 KO_1.3 cells, and $\mathrm{IC}_{50}$ was not reached at $50 \mathrm{nM}$ in wild-type $\mathrm{H} 460$ cells. Our results showing that cells lacking TDP1 have hypersensitivity to topotecan are indicative that TDP1 is critical for the repair of DNA damage (measured by increased H2AX), which is consistent with previous studies $[18,19]$.

One of the curious findings in our cell proliferation experiments was that different cell lines have different sensitivity towards topotecan on its own or in combination with DJ009. We reasoned that TDP1 abundance may

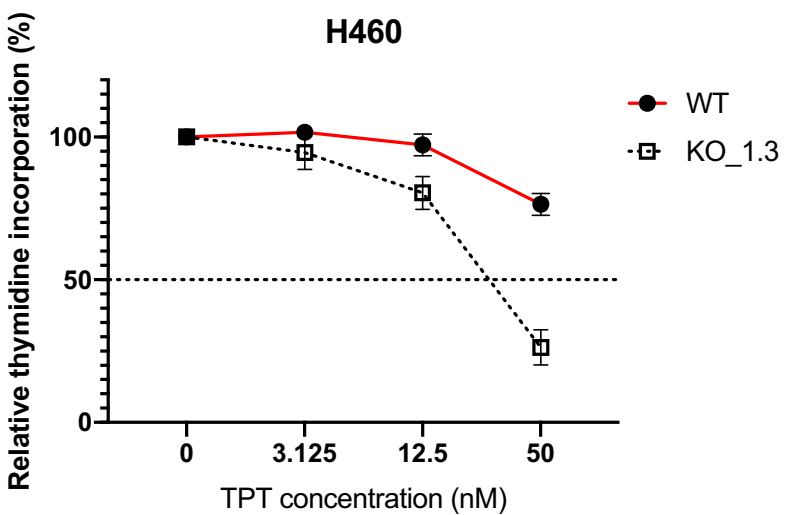

of cells to topotecan, with the greatest effect observed in H460 cells. Data are mean \pm SE of three independent experiments

influence the sensitivity of the cell lines to topotecan tested in this study. To test this hypothesis, we investigated the expression level of TDP1 protein in the panel of cell lines. Immunoblotting showed that TDP1 is expressed in all the cell lines tested, although the level is relatively low in the pancreatic cancer cell lines MiaPaCa and PANC1, and lung cancer cell line A549 (see Supporting Information, Figure S12). We also computed Pearson correlation coefficients between the sensitivity of 358 diverse cancer cell lines to topoisomerase I inhibitors irinotecan/topotecan and their TDP1 mRNA expression using data downloaded from the Cancer Dependency Map portal (see Supporting Information, Figure S13). By applying network correlation analysis, we found that the correlation between TDP1 mRNA expression and the potency of topoisomerase I inhibitors is very weak (median $r=-0.3$ ). This analysis suggests that elevated TDP1 expression cannot predict the sensitivity of cancer cells towards topoisomerase I inhibitors, an observation that is in agreement with previous studies [80-82]. The finding from the network correlation analysis is also consistent with our experimental results showing that the sensitivity to topotecan or the combination effect of DJ009 and topotecan was not correlated with the protein expression. For example, SKBR3 showed similar TDP1 expression level to H460 cells (see Supporting Information, Figure S12), but no significant 

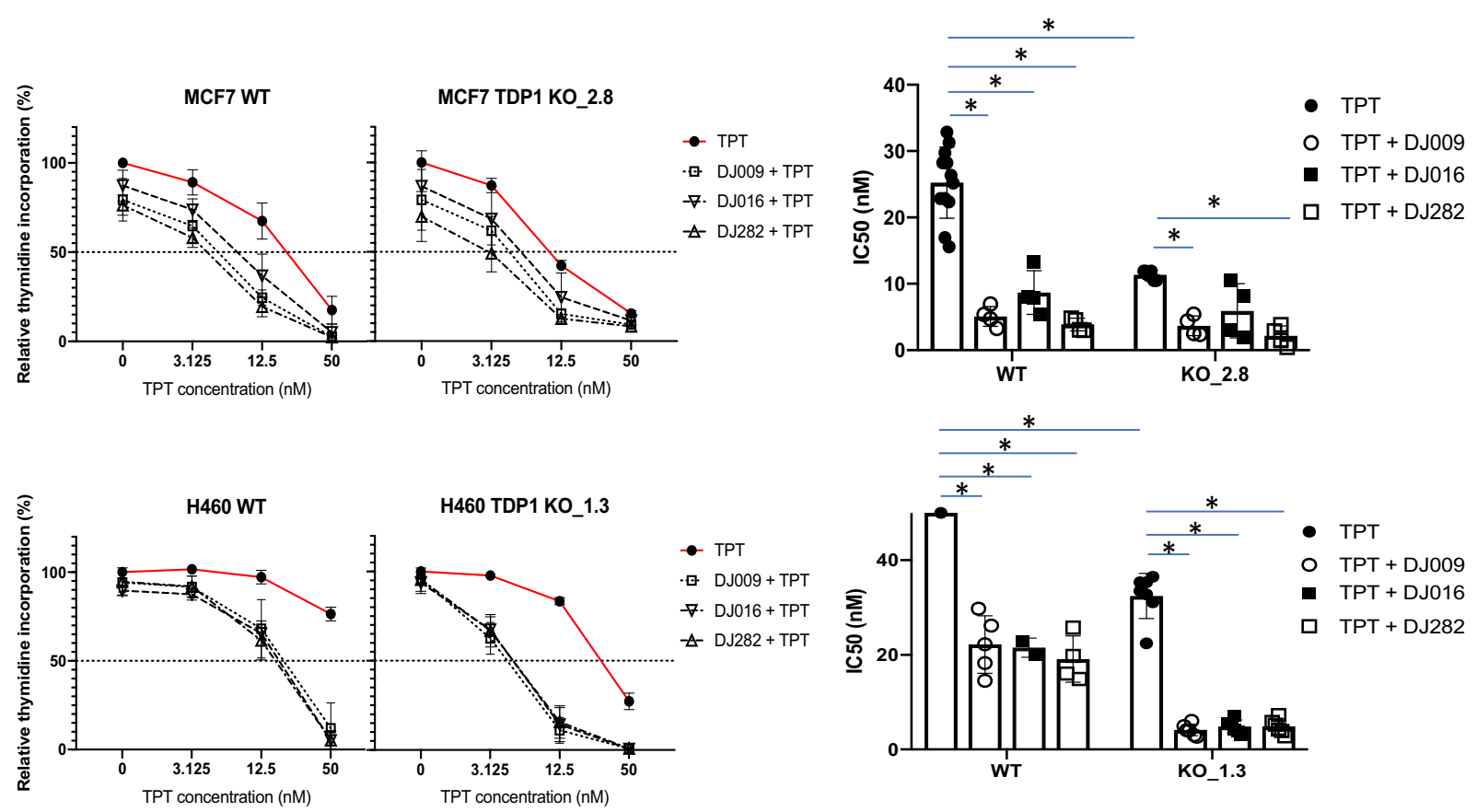

Fig. 4 The dose response plots and corresponding bar graphs with the $\mathrm{IC}_{50}$ values of the different potency of each compound in combination with topotecan the WT and the corresponding TDP1 knockout (KO) in

difference was observed in the treatment of topotecan alone or in combination with DJ009 in the SKBR3 cell line (as opposed to H460, which showed a significant potentiation effect) (see Supporting Information, Figure S10).

Thieno[2,3-b]pyridines have many different targets [35, 38, 69, 73, 76, 77], and off-target toxicity is also commonly reported in cancer drug candidates. We therefore exposed MCF7 and H460 KO clones to TDP1 inhibitors and topotecan concomitantly to examine potential off-target effects. Unexpectedly, all three inhibitors tested also sensitized the TDP1 KO cells to topotecan antiproliferative effects apart from DJ016 in the MCF7 knockout KO_2.8 cell line (Fig. 4), indicating that these compounds are modulating other pathways that may contribute to the observed potentiation effect of topotecan. Previous studies have proposed that TDP2 and poly(ADP-ribose)polymerase 1 (PARP1) may aid the repair of DNA strand breaks caused by topoisomerase I inhibitors $[39,40,83]$. To determine whether the (a) MCF7 breast cancer cell line and b $\mathrm{H} 460$ lung cancer cell line. The concentration of each TDP1 inhibitor was $430 \mathrm{nM}$ for all the experiments. ${ }^{*} p<0.05$ and data are mean $\pm S E$ of three independent experiments

potentiation effects observed with the $\mathrm{KO}$ cell lines were due to thieno[2,3- $b]$ pyridines targeting TDP2, we tested the potentiation effect of DJ009, DJ016 or DJ282 with topoisomerase II inhibitor (doxorubicin). This is because TDP2 has been reported to be involved in the repair of topoisomerase II inhibitor-induced damage $[84,85]$. However, our results showed that there are no synergistic effects between DJ009/DJ016 and doxorubicin (see Supporting Information, Figure S14). The only exception is DJ282 in MCF7 cells. However, as DJ282 showed some inhibitory effect towards MCF7 cell growth in the absence of doxorubicin, the additional reduced proliferation by DJ282 is not likely due to enhancement of doxorubicin inhibition. Hence, our data indicate that DJ009, DJ016 and DJ282 can selectively enhance the efficacy of topoisomerase I inhibitor topotecan but not topoisomerase II inhibitor doxorubicin; i.e., thieno[2,3-b]pyridines are unlikely to target TDP2. In contrast, we found that PARP1 inhibitor olaparib can further sensitize the cancer 
cells to topotecan (see Supporting Information, Figure S15). Proliferation assay showed a potentiating effect in MCF7 and H460 cells treated with olaparib and topotecan. The synergistic interaction between olaparib, DJ009 and topotecan was most notable in the H460 cell line (see Supporting Information, Figure S15). Although it is not clear whether our thieno[2,3$b$ ]pyridine compounds are directly targeting PARP1 or its downstream/upstream pathway(s) (in addition to targeting TDP1), our results collectively showed that sensitivity to topoisomerase I inhibitors is likely to be modulated by multiple DNA repair enzymes, including TDP1 and PARP1.

\section{DISCUSSION}

Topoisomerase I inhibitors such as topotecan and irinotecan are clinically used chemotherapeutic agents that have shown to be highly effective in the treatments of a number of cancers including ovarian cancer, colorectal cancer, small cell lung cancer and cervical cancer. The development of resistance against topoisomerase I inhibitors is a major obstacle for the successful treatments of these cancers. Extensive work has been conducted in the last two decades to develop chemosensitizers for topoisomerase I poisons to help delay or reverse their chemoresistance. Several DNA repair pathways, including (but not limited to) those mediated by TDP1, TDP2 and PARP1, have been proposed to be involved in repairing topoisomerase I-mediated DNA damage, and hence they are potential inhibition targets to improve the efficiency of topoisomerase I poisons. In particular, TDP1 is a potentially important target as it is directly involved in the release of the stalled topoisomerase I-DNA cleavage complexes that is caused by topoisomerase I inhibitors. Hence, in this study, we set out to validate TDP1 as an inhibition target for the development of new chemosensitizers against topoisomerase I poisons.

By using thieno[2,3- $b]$ pyridines, a class of compounds that we have shown to be highly potent against TDP1, as model compounds, we showed that inhibition of TDP1 can restore sensitivity to topoisomerase I inhibitors such as topotecan in some cancer cell lines. This is supported by the CRISPR/Cas9 knockout cell experiments. Hence, our results validate TDP1 as a target for the development of new chemosensitizers against topoisomerase I poisons. However, our results also revealed a more complex picture. Firstly, we found that sensitivity towards topotecan and the combination of topotecan and thieno[2,3-b]pyridines differs between different cell lines, and is not necessarily linked to the expression of TDP1. Secondly, we found that thieno[2,3-b]pyridines also induced a potentiation effect of topotecan in TDP1 knockout cells, showing that our thieno[2,3-b]pyridines are not specific to TDP1. These implied that the sensitivity towards topoisomerase I inhibitors that we observed is likely being modulated by multiple pathways, of which TDP1 is only one. Our results using topoisomerase II poisons and PARP1 inhibitors showed that pathway(s) modulated by PARP1 are likely candidate(s), although it is also highly possible that other redundant and partially overlapping pathways may be involved in the DNA repair process.

Our work also exposes challenges and opportunities in the development of chemosensitizers for topoisomerase I inhibitors. Firstly, our results help establish TDP1 as a desirable inhibition target for the development of chemosensitizers against topoisomerase I poisons. It also opens the possibility of targeting multiple DNA repair pathways to further increase the sensitivity towards topoisomerase I inhibitors. This is an area that warrants further research, as it may significantly improve clinical outcomes and maximize the potential for topoisomerase I inhibitor-based treatments. It is important to note, however, that thieno[2,3$b$ ]pyridines only showed synergistic effects with topotecan in some cell lines. Further work is therefore needed to fully understand the reasons behind this observation. For example, it is possible that the intrinsic responsiveness and/or activity of DNA repair pathways between cell lines are different. It is also possible that there may exist other DNA repair pathway(s) (that do not respond to thieno[2,3- $b]$ pyridines) that are more dominant in some cancer cells. Secondly, 
our results showed that a better biomarker (or set of biomarkers) than TDP1 is needed to aid the prediction of sensitivity towards topoisomerase I inhibitors. The elucidation of the complete network of pathways that is involved in the repair of DNA damage caused by topoisomerase I inhibitors would be very helpful for biomarker identification. A more complete understanding of the intricate human DNA damage response and repair network would also help in the identification of further inhibition targets for the development of new chemosensitizers. One possible strategy to map the possible DNA repair pathways that are involved in repairing damage caused by topoisomerase I inhibitors is to design photocrosslinking chemical probes based on our thieno[2,3$b$ ]pyridines. This may enable the identification of proteins and enzymes (other than TDP1) that interact with our thieno[2,3- $b]$ pyridine compounds.

\section{CONCLUSIONS}

Overall, by using thieno[2,3- $b]$ pyridines, a class of TDP1 inhibitors that we had previously developed, we showed that the inhibition of TDP1 can restore sensitivity to topotecan in some cell lines. However, experiments with TDP1 knockout cells showed that thieno[2,3b]pyridines are not specific to TDP1, as we found that thieno[2,3-b]pyridines could also potentiate the effect of topoisomerase I poisons in TDP1 knockout cells. To further investigate this redundancy, we probed whether TDP2 and PARP1 are involved in repairing topoisomerase I inhibitor-induced DNA damage. We found that PARP1 inhibitor olaparib can further sensitize the effect of topoisomerase I poisons in the presence of thieno[2,3-b]pyridines, indicating that the PARP1 pathway is complementary to the TDP1 pathway in repairing damage cause by topoisomerase I inhibitors. Our work therefore opens up the avenue of targeting and inhibiting enzymes from multiple DNA repair pathways simultaneously to increase the sensitivity to topoisomerase I inhibitors.

\section{ACKNOWLEDGEMENTS}

We thank Alexandra L. Zakharenko of the Novosibirsk Institute of Chemical Biology and Fundamental Medicine for her helpful discussions on the TDP1 oligonucleotide-based fluorescence assay.

Funding. We thank the financial support of the University of Auckland and the Auckland Cancer Society Research Centre. E.L. acknowledges the support of a Belinda Scott Science Fellowship from the New Zealand Breast Cancer Foundation, a Lottery Health Research Grant from the New Zealand Government, and a research project grant from the Cancer Research Trust New Zealand. D.B. acknowledges the support of a research grant from the Cancer Society of New Zealand (20.23). P.T. acknowledges the support from a John Gavin Post-doctoral Fellowship (GOT 1717 JGPDF) awarded to P.T. by Cancer Research Trust New Zealand. Sponsorship for the Rapid Service Fee was funded by the Cancer Research Trust New Zealand.

Authorship. All named authors had full access to all of the data in this study, meet the International Committee of Medical Journal Editors (ICMJE) criteria for authorship for this article, take responsibility for the integrity of the work as a whole, and have given their approval for this version to be published.

Authors' Contribution. Conceptualization: Euphemia Leung, Jóhannes Reynisson, Ivanhoe K. H. Leung; Methodology: Euphemia Leung, Jinal Patel, Jennifer A. Hollywood, Ayesha Zafar, Petr Tomek, David Barker, Lisa I. Pilkington, Michelle van Rensburg, Ries J. Langley, Nuala A. Helsby, Christopher J. Squire, Bruce C. Baguley, William A. Denny, Jóhannes Reynisson, Ivanhoe K. H. Leung; Formal analysis and investigation: Euphemia Leung, Jinal Patel, Jennifer A. Hollywood, Ayesha Zafar, Petr Tomek, David Barker, Lisa I. Pilkington, Michelle van Rensburg, Ries J. Langley, Nuala A. Helsby, Christopher J. Squire, Bruce C. Baguley, William A. Denny, Jóhannes Reynisson, Ivanhoe K. H. Leung; Writing-original draft preparation: 
Euphemia Leung, Jinal Patel, Jóhannes Reynisson, Ivanhoe K. H. Leung; Writing-review and editing: Euphemia Leung, Jinal Patel, Jennifer A. Hollywood, Ayesha Zafar, Petr Tomek, David Barker, Lisa I. Pilkington, Michelle van Rensburg, Ries J. Langley, Nuala A. Helsby, Christopher J. Squire, Bruce C. Baguley, William A. Denny, Jóhannes Reynisson, Ivanhoe K. H. Leung; Funding acquisition: Euphemia Leung, Petr Tomek, David Barker, Jóhannes Reynisson, Ivanhoe K. H. Leung; Resources: Euphemia Leung, David Barker, Christopher J. Squire, Jóhannes Reynisson, Ivanhoe K. H. Leung; Supervision: Euphemia Leung, David Barker, Lisa I. Pilkington, Christopher J. Squire, Jóhannes Reynisson, Ivanhoe K. H. Leung.

Disclosures. Euphemia Leung, Jinal Patel, Jennifer A. Hollywood, Ayesha Zafar, Petr Tomek, David Barker, Lisa I. Pilkington, Michelle van Rensburg, Ries J. Langley, Nuala A. Helsby, Christopher J. Squire, Bruce C. Baguley, William A. Denny, Jóhannes Reynisson and Ivanhoe K. H. Leung have nothing to declare.

Compliance with Ethics Guidelines. Ethical committee approval was not required as no human, animal or human embryonic stem cells were used in the study. Our gene editing experiments were operated under the New Zealand HSNO approval (GM005-UA0022). The use of genetically modified $E$. coli for recombinant protein production was operated under the University of Auckland-wide approval (APP202708) by the New Zealand Environmental Protection Authority.

Data Availability. All data generated or analyzed during this study are included in this published article/as supplementary information files.

Open Access. This article is licensed under a Creative Commons Attribution-NonCommercial 4.0 International License, which permits any non-commercial use, sharing, adaptation, distribution and reproduction in any medium or format, as long as you give appropriate credit to the original author(s) and the source, provide a link to the Creative Commons licence, and indicate if changes were made. The images or other third party material in this article are included in the article's Creative Commons licence, unless indicated otherwise in a credit line to the material. If material is not included in the article's Creative Commons licence and your intended use is not permitted by statutory regulation or exceeds the permitted use, you will need to obtain permission directly from the copyright holder. To view a copy of this licence, visit http://creativecommons.org/licenses/by$\mathrm{nc} / 4.0 /$.

\section{REFERENCES}

1. Guestini F, McNamara KM, Sasano H. The use of chemosensitizers to enhance the response to conventional therapy in triple-negative breast cancer patients. Breast Cancer Manag. 2018;6:127-31.

2. Michod D, Widmann C. DNA-damage sensitizers: potential new therapeutical tools to improve chemotherapy. Crit Rev Oncol Hematol. 2007;63: 160-71.

3. Martino E, Della Volpe S, Terribile E, Benetti E, Sakaj M, Centamore A, Sala A, Collina S. The long story of camptothecin: from traditional medicine to drugs. Bioorg Med Chem Lett. 2017;27:701-7.

4. Venditto VJ, Simanek EE. Cancer therapies utilizing the camptothecins: a review of in vivo literature. Mol Pharm. 2010;7:307-49.

5. Thomas CJ, Rahier NJ, Hecht SM. Camptothecin: current perspectives. Bioorg Med Chem. 2004;12: 1585-604.

6. Capranico G, Marinello J, Chillemi G. Type I DNA topoisomerases. J Med Chem. 2017;60:2169-92.

7. Hartman Chen S, Chan N-L, Hsieh T-S. New mechanistic and functional insights into DNA topoisomerases. Annu Rev Biochem. 2013;82: 139-70.

8. Liu LR, Desai SD, Li T-K, Mao Y, Sun M, Sim S-P. Mechanism of action of camptothecin. Ann N Y Acad Sci. 2000;922:1-10.

9. Hertzberg RP, Caranfa MJ, Hecht SM. On the mechanism of topoisomerase I inhibition by camptothecin: evidence for binding to an enzymeDNA complex. Biochemistry. 1989;28:4629-38. 
10. Nickoloff JA, Jones D, Lee S-H, Williamson EA, Hromas R. Drugging the cancers addicted to DNA repair. J Natl Cancer Inst. 2017;109:djx059.

11. Alagoz M, Gilbert DC, El-Khamisy S, Chalmers AJ. DNA repair and resistance to topoisomerase I inhibitors: mechanisms, biomarkers and therapeutic targets. Curr Med Chem. 2012;19:3874-85.

12. Beretta GL, Gatti L, Perego P, Zaffaroni N. Camptothecin resistance in cancer: insights into the molecular mechanisms of a DNA-damaging drug. Curr Med Chem. 2013;20:1541-65.

13. Heo J, Li J, Summerlin M, Hays A, Katyal S, McKinnon PJ, Nitiss KC, Nitiss JL, Hanakahi LA. TDP1 promotes assembly of non-homologous end joining protein complexes on DNA. DNA Repair. 2015;30:28-37.

14. Interthal $\mathrm{H}$, Pouliot JJ, Champoux JJ. The tyrosylDNA phosphodiesterase Tdp1 is a member of the phospholipase D superfamily. Proc Natl Acad Sci USA. 2001;98:12009-14.

15. Pouliot JJ, Yao KC, Robertson CA, Nash HA. Yeast gene for a Tyr-DNA phosphodiesterase that repairs topoisomerase I complexes. Science. 1999;286: $552-5$.

16. Jakobsen A-K, Lauridsen KL, Samuel EB, Proszek J, Knudsen BR, Hager H, Stougaard M. Correlation between topoisomerase I and tyrosyl-DNA phosphodiesterase 1 activities in non-small cell lung cancer tissue. Exp Mol Pathol. 2015;99:56-64.

17. Barthelmes HU, Habermeyer M, Christensen MO, Mielke C, Interthal H, Pouliot JJ, Boege F, Marko D. TDP1 overexpression in human cells counteracts DNA damage mediated by topoisomerases I and II. J Biol Chem. 2004;279:55618-25.

18. Murai J, Huang S-YN, Das BB, Dexheimer TS, Takeda S, Pommier Y. Tyrosyl-DNA phosphodiesterase 1 (TDP1) repairs DNA damage induced by topoisomerases I and II and base alkylation in vertebrate cells. J Biol Chem. 2012;287:12848-57.

19. Interthal $\mathrm{H}$, Chen $\mathrm{HJ}$, Kehl-Fie TE, Zotzmann J, Leppard JB, Champoux JJ. SCAN1 mutant Tdp1 accumulates the enzyme-DNA intermediate and causes camptothecin hypersensitivity. EMBO J. $2005 ; 24: 2224-33$.

20. Salomatina OV, Popadyuk II, Zakharenko AL, Zakharova OD, Chepanova AA, Dyrkheeva NS, Komarova NI, Reynisson J, Anarbaev RO, Salakhutdinov NF, Lavrik OI, Volcho KP. Deoxycholic acid as a molecular scaffold for tyrosyl-DNA phosphodiesterase 1 inhibition: a synthesis, structure-activity relationship and molecular modeling study. Steroids. 2021;165:108771.
21. Gladkova ED, Nechepurenko IV, Bredikhin RA, Chepanova AA, Zakharenko AL, Luzina OA, Ilina ES, Dyrkheeva NS, Mamontova EM, Anarbaev RO, Reynisson J, Volcho KP, Salakhutdinov NF, Lavrik OI. The first berberine-based inhibitors of tyrosylDNA phosphodiesterase 1 (Tdp1), an important DNA repair enzyme. Int J Mol Sci. 2020;21:7162.

22. Il'ina IV, Dyrkheeva NS, Zakharenko AL, Sidorenko $\mathrm{AYu}$, Li-Zhulanov NS, Korchagina DV, Chand R, Ayine-Tora DM, Chepanova AA, Zakharova OD, Ilina ES, Reynisson J, Malakhova AA, Medvedev SP, Zakian SM, Volcho KP, Salakhutdinov NF, Lavrik OI. Design, synthesis, and biological investigation of novel classes of 3-carene-derived potent inhibitors of TDP1. Molecules. 2020;25:3496.

23. Mamontova EM, Zakharenko AL, Zakharova OD, Dyrkheeva NS, Volcho KP, Reynisson J, Arabshahi HJ, Salakhutdinov NF, Lavrik OI. Identification of novel inhibitors for the tyrosyl-DNA-phosphodiesterase 1 (Tdp1) mutant SCAN1 using virtual screening. Bioorg Med Chem. 2020;28:115234.

24. Khomenko TM, Zakharenko AL, Chepanova AA, Ilina ES, Zakharova OD, Kaledin VI, Nikolin VP, Popova NA, Korchagina DV, Reynisson J, Chand R, Ayine-Tora DM, Patel J, Leung IKH, Volcho KP, Salakhutdinov NF, Lavrik OI. Promising new inhibitors of tyrosyl-DNA phosphodiesterase I (Tdp 1) combining 4-arylcoumarin and monoterpenoid moieties as components of complex antitumor therapy. Int J Mol Sci. 2020;21:126.

25. Chepanova AA, Li-Zhulanov NS, Sukhikh AS, Zafar A, Reynisson J, Zakharenko AL, Zakharova OD, Korchagina DV, Volcho KP, Salakhutdinov NF, Lavrik OI. Effective inhibitors of tyrosyl-DNA phosphodiesterase 1 based on monoterpenoids as potential agents for antitumor therapy. Russ J Bioorg Chem. 2019;45:647-55.

26. Mozhaitsev E, Suslov E, Demidova Y, Korchagina D, Volcho K, Zakharenko A, Vasil'eva I, Kupryushkin M, Chepanova A, Ayine-Tora DM, Reynisson J, Salakhutdinov N, Lavrik O. The development of tyrosyl-DNA phosphodyesterase 1 (TDP1) inhibitors based on the amines combining aromatic/ heteroaromatic and monoterpenoid moieties. Lett Drug Des Discov. 2019;16:597-605.

27. Chepanova AA, Mozhaitsev ES, Munkuev AA, Suslov EV, Korchagina DV, Zakharova OD, Zakharenko AL, Patel J, Ayine-Tora DM, Reynisson J, Leung IKH, Volcho KP, Salakhutdinov NF, Lavrik OI. The development of tyrosyl-DNA phosphodiesterase 1 inhibitors. Combination of monoterpene and adamantine moieties via amide or thioamides bridges. Appl Sci. 2019;9:2767.

28. Filimonov AS, Chepanova AA, Luzina OA, Zakharenko AL, Zakharova OD, Ilina ES, Dyrkheeva NS, 
Kuprushkin MS, Kolotaev AV, Khachatryan DS, Patel J, Leung IKH, Chand R, Ayine-Tora DM, Reynisson J, Volcho KP, Salakhutdinov NF, Lavrik OI. New hydrazinothiazole derivatives of usnic acid as potent Tdp1 inhibitors. Molecules. 2019;24: 3711 .

29. Mozhaitsev ES, Zakharenko AL, Suslov EV, Korchagina DV, Zakharova OD, Vasil'eva IA, Chepanova AA, Black E, Patel J, Chand R, Reynisson J, Leung IKH, Volcho KP, Salakhutdinov NF, Lavrik OI. Novel inhibitors of DNA repair enzyme TDP1 combining monoterpenoid and adamantane fragments. Anti-Cancer Agents Med Chem. 2019;19: 463-72.

30. Zakharova O, Luzina O, Zakharenko A, Sokolov D, Filimonov A, Dyrkheeva N, Chepanova A, Ilina E, Ilyina A, Klabenkova K, Chelobanov B, Stetsenko D, Zafar A, Eurtivong C, Reynisson J, Volcho K, Salakhutdinov N, Lavrik O. Synthesis and evaluation of aryliden- and hetarylidenfuranone derivatives of usnic acid as highly potent Tdp1 inhibitors. Bioorg Med Chem. 2018;26:4470-80.

31. Zakharenko AL, Luzina OA, Sokolov DN, Kaledin VI, Nikolin VP, Popova NA, Patel J, Zakharova OD, Chepanova AA, Zafar A, Reynisson J, Leung E, Leung IKH, Volcho KP, Salakhutdinov NF, Lavrik OI. Novel tyrosyl-DNA phosphodiesterase 1 inhibitors enhance the therapeutic impact of topotecan on in vivo tumor models. Eur J Med Chem. 2019;161:581-93.

32. Li-Zhulanov NS, Zakharenko AL, Chepanova AA, Patel J, Zafar A, Volcho KP, Salakhutdinov NF, Reynisson J, Leung IKH, Lavrik OI. A novel class of tyrosyl-DNA phosphodiesterase 1 inhibitors that contains the octahydro- $2 \mathrm{H}$-chromen-4-ol scaffold. Molecules. 2018;23:2468.

33. Ponomarev KY, Suslov EV, Zakharenko AL, Zakharova OD, Rogachev AD, Korchagina DV, Zafar A, Reynisson J, Nefedov AA, Volcho KP, Salakhutdinov NF, Lavrik OI. Aminoadamantanes containing monoterpene-derived fragments as potent tyrosyl-DNA phosphodiesterase 1 inhibitors. Bioorg Chem. 2018;76:392-9.

34. Salomatina OV, Popadyuk II, Zakharenko AL, Zakharova OD, Fadeev DS, Komarova NI, Reynisson J, Arabshahi HJ, Chand R, Volcho KP, Salakhutdinov NF, Lavrik OI. Novel semisynthetic derivatives of bile acids as effective tyrosyl-DNA phosphodiesterase 1 inhibitors. Molecules. 2018;23:679.

35. Zafar A, Sari S, Leung E, Pilkington LI, van Rensburg M, Barker D, Reynisson J. GPCR modulation of thieno[2,3- $b$ ]pyridine anti-proliferative agents. Molecules. 2017;22:2254.
36. Khomenko T, Zakharenko A, Odarchenko T, Arabshahi HJ, Sannikova V, Zakharova O, Korchagina D, Reynisson J, Volcho K, Salakhutdinov N, Lavrik O. New inhibitors of tyrosyl-DNA phosphodiesterase I (Tdp 1) combining 7-hydroxycoumarin and monoterpenoid moieties. Bioorg Med Chem. 2016;24:5573-81.

37. Zakharenko A, Khomenko T, Zhukova S, Koval O, Zakharova O, Anarbaev R, Lebedeva N, Korchagina D, Komarova N, Vasiliev V, Reynisson J, Volcho K, Salakhutdinov N, Lavrik O. Synthesis and biological evaluation of novel tyrosyl-DNA phosphodiesterase 1 inhibitors with a benzopentathiepine moiety. Bioorg Med Chem. 2015;23:2044-52.

38. Arabshahi HJ, van Rensburg M, Pilkington LI, Jeon CY, Song M, Gridel L-M, Leung E, Barker D, VuicaRoss M, Volcho KP, Zakharenko AL, Lavrik OI, Reynisson J. A synthesis, in silico, in vitro and in vivo study of thieno[2,3- $b$ ]pyridine anticancer analogues. Med Chem Commun. 2015;6:1987-97.

39. Fam HK, Walton C, Mitra SA, Chowdhury M, Osborne N, Choi K, Sun G, Wong PCW, O'Sullivan MJ, Turashvili G, Aparicio S, Triche TJ, Bond M, Pallen CJ, Boerkoel CF. TDP1 and PARP1 deficiency are cytotoxic to rhabdomyosarcoma cells. Mol Cancer Res. 2013;11:1179-92.

40. Zeng Z, Sharma A, Ju L, Murai J, Umans L, Vermeire L, Pommier Y, Takeda S, Huylebroeck D, Caldecott KW, El-Khamisy SF. TDP2 promotes repair of topoisomerase I-mediated DNA damage in the absence of TDP1. Nucleic Acids Res. 2012;40: 8371-80.

41. Deng C, Brown JA, You D, Brown JM. Multiple endonucleases function to repair covalent topoisomerase I complexes in Saccharomyces cerevisiae. Genetics. 2005;170:591-600.

42. Vance JR, Wilson TE. Yeast Tdp1 and Rad1-Rad10 function as redundant pathways for repairing Top1 replicative damage. Proc Natl Acad Sci USA. 2002;99:13669-74.

43. Liu C, Pouliot JJ, Nash HA. Repair of topoisomerase I covalent complexes in the absence of the tyrosylDNA phosphodiesterase Tdp1. Proc Natl Acad Sci USA. 2002;99:14970-5.

44. Leung EY, Kim JE, Askarian-Amiri M, Rewcastle GW, Finlay GJ, Baguley BC. Relationships between signaling pathway usage and sensitivity to a pathway inhibitor: examination of trametinib responses in cultured breast cancer lines. PLoS ONE. 2014;9: e105792.

45. Leung E, Kannan N, Krissansen GW, Findlay MP, Baguley BC. MCF7 breast cancer cells selected for tamoxifen resistance acquire new phenotypes 
differing in DNA content, phospho-HER2 and PAX2 expression, and rapamycin sensitivity. Cancer Biol Ther. 2010;9:717-24.

46. Li J, Summerlin M, Nitiss KC, Nitiss JL, Hanakahi LA. TDP1 is required for efficient non-homologous end joining in human cells. DNA Repair. 2017;60: $40-9$.

47. Ran FA, Hsu PD, Wright J, Agarwala V, Scott DA, Zhang F. Genome engineering using the CRISPRCas9 system. Nat Protoc. 2013;8:2281-307.

48. Berenbaum MC. Criteria for analyzing interactions between biologically active agents. Adv Cancer Res. 1981;35:269-335.

49. Lountos GT, Zhao XZ, Kiselev E, Tropea JE, Needle D, Pommier Y, Burke TR, Waugh DS. Identification of a ligand binding hot spot and structural motifs replicating aspects of tyrosyl-DNA phosphodiesterase I (TDP1) phosphoryl recognition by crystallographic fragment cocktail screening. Nucleic Acids Res. 2019;47:10134-50.

50. Berman HM, Westbrook J, Feng Z, Gilliland G, Bhat $\mathrm{TN}$, Weissig $\mathrm{H}$, Shindyalov IN, Bourne PE. The protein data bank. Nucleic Acids Res. 2000;28: 235-42.

51. Berman H, Henrick K, Nakamura H. Announcing the worldwide protein data bank. Nat Struct Biol. 2003;10:980.

52. Scigress Ultra V, F.J 2.6. (EU 3.1.7); Fujitsu Limited: 2008-2016.

53. Allinger NL. Conformational analysis. 130. MM2. A hydrocarbon force field utilizing V1 and V2 torsional terms. J Am Chem Soc. 1977;99:8127-34.

54. Gotō H, Ōsawa E. An efficient algorithm for searching low-energy conformers of cyclic and acyclic molecules. J Chem Soc, Perkin Trans 2. 1993;2:187-98.

55. Jones G, Willet P, Glen RC, Leach AR, Taylor R. Development and validation of a genetic algorithm for flexible docking. J Mol Biol. 1997;267:727-48.

56. Eldridge MD, Murray C, Auton TR, Paolini GV, Mee PM. Empirical scoring functions: I. The development of a fast empirical scoring function to estimate the binding affinity of ligands in receptor complexes. J Comp Aid Mol Design. 1997;11: 425-45.

57. Verdonk ML, Cole JC, Hartshorn MJ, Murray CW, Taylor RD. Improved protein-ligand docking using GOLD. Proteins. 2003;52:609-23.
58. Korb O, Stützle T, Exner TE. Empirical scoring functions for advanced protein-ligand docking with PLANTS. J Chem Inf Model. 2009;49:84-96.

59. Mooij WTM, Verdonk ML. General and targeted statistical potentials for protein-ligand interactions. Proteins. 2005;61:272-87.

60. Taira Z, Terada H. Specific and non-specific ligand binding to serum albumin. Biochem Pharmacol. 1985;34:1999-2005.

61. McPhillips TM, McPhillips SE, Chiu H-J, Cohen AE, Deacon AM, Ellis PJ, Garman E, Gonzalez A, Sauter NK, Phizackerley RP. Blu-Ice and the distributed control system: software for data acquisition and instrument control at macromolecular crystallography beamlines. J Synchrotron Rad. 2002;9:401-6.

62. Kabsch W. Integration, scaling, space-group assignment and post-refinement. Acta Crystallogr D Biol Crystallogr. 2010;66:133-44.

63. Evans PR, Murshudov GN. How good are my data and what is the resolution? Acta Crystallogr D Biol Crystallogr. 2013;69:1204-14.

64. McCoy AJ, Grosse-Kunstleve RW, Adams PD, Winn MD, Storoni LC, Read RJ. Phaser crystallographic software. J Appl Crystallogr. 2007;40:658-74.

65. Davies DR, Interthal $\mathrm{H}$, Champoux JJ, Hol WGJ. The crystal structure of human tyrosyl-DNA phosphodiesterase, Tdp1. Structure. 2002;10:237-48.

66. Murshudov GN, Skubák P, Lebedev AA, Pannu NS, Steiner RA, Nicholls RA, Winn MD, Long F, Vagin AA. REFMAC5 for the refinement of macromolecular crystal structures. Acta Crystallogr D Biol Crystallogr. 2011;67:355-67.

67. Emsley P, Cowtan K. Coot: model-building tools for molecular graphics. Acta Crystallogr D Biol Crystallogr. 2004;60:2126-32.

68. Chaudhari R, Li Z. PyMine: a PyMOL plugin to integrate and visualize data for drug discovery. BMC Res Notes. 2015;8:517.

69. Binsaleh NK, Wigley CA, Whitehead KA, van Rensburg M, Reynisson J, Pilkington LI, Barker D, Jones S, Dempsey-Hibbert NC. Thieno[2,3-b]pyridine derivatives are potent anti-platelet drugs, inhibiting platelet activation, aggregation and showing synergy with aspirin. Eur J Med Chem. 2018;143:1997-2004.

70. Zafar A, Pilkington LI, Haverkate NA, Van Rensburg M, Leung E, Kumara S, Denny WA, Barker D, Alsuraifi A, Hoskins C, Reynisson J. Investigation into improving the aqueous solubility of the 
thieno[2,3- $b$ ]pyridine anti-proliferative agents. Molecules. 2018;23:145.

71. Mastelić A, Čulić VČ, Mužinić NR, Vuica-Ross M, Barker D, Leung EY, Reynisson J, Markotić A. Glycophenotype of breast and prostate cancer stem cells treated with thieno[2,3-b]pyridine anticancer compound. Drug Des Devel Ther. 2017;11:759-69.

72. van Rensburg M, Leung E, Haverkate NA, Eurtivong C, Pilkington LI, Reynisson J, Barker D. Synthesis and antiproliferative activity of 2-chlorophenyl carboxamide thienopyridines. Bioorg Med Chem Lett. 2017;27:135-8.

73. Reynisson J, Jaiswal JK, Barker D, D'mello SAN, Denny WA, Baguley BC, Leung EY. Evidence that phospholipase $\mathrm{C}$ is involved in the antitumour action of NSC768313, a new thieno[2,3-b]pyridine derivative. Cancer Cell Int. 2016;16:18.

74. Leung E, Pilkington LI, van Rensburg M, Jeon CY, Song M, Arabshahi HJ, De Zoysa GH, Sarojini V, Denny WA, Reynisson J, Barker D. Synthesis and cytotoxicity of thieno[2,3-b]quinoline-2-carboxamide and cycloalkyl[b]thieno[3,2-e]pyridine-2carboxamide derivatives. Bioorg Med Chem. 2016;24:1142-54.

75. Hung JM, Arabshahi HJ, Leung E, Reynisson J, Barker D. Synthesis and cytotoxicity of thieno[2,3b]pyridine and furo[2,3-b]pyridine derivatives. Eur J Med Chem. 2014;86:420-37.

76. Arabshahi HJ, Leung E, Barker D, Reynisson J. The development of thieno[2,3-b]pyridine analogues as anticancer agents applying in silico methods. Med Chem Commun. 2014;5:186-91.

77. Leung E, Hung JM, Barker D, Reynisson J. The effect of a thieno[2,3-b]pyridine PLC- $\gamma$ inhibitor on the proliferation, morphology, migration and cell cycle of breast cancer cells. Med Chem Commun. 2014;5: 99-106.

78. Walker S, Meisenberg C, Bibby RA, Askwith T, Williams G, Rininsland FH, Pearl LH, Oliver AW, ElKhamisy S, Ward S, Atack JR. Development of an oligonucleotide-based fluorescence assay for the identification of tyrosyl-DNA phosphodiesterase 1 (TDP1) inhibitors. Anal Biochem. 2014;454:17-22.

79. Sharma A, Singh K, Almasan A. Histone H2AX phosphorylation: a marker for DNA damage. Methods Mol Biol. 2012;920:613-26.

80. Tesauro C, Simonsen AK, Andersen MB, Petersen KW, Kristoffersen EL, Algreen L, Yokoyama Hansen $\mathrm{N}$, Andersen AB, Jakobsen AK, Stougaard M, Gromov P, Knudsen BR, Gromova I. Topoisomerase I activity and sensitivity to camptothecin in breast cancer-derived cells: a comparative study. BMC Cancer. 2019;19:1158.

81. Meisenberg C, Gilbert DC, Chalmers A, Haley V, Gollins S, Ward SE, El-Khamisy SF. Clinical and cellular roles for TDP1 and TOP1 in modulating colorectal cancer response to irinotecan. Mol Cancer Ther. 2015;14:575-85.

82. Meisenberg C, Ward SE, Schmid P, El-Khamisy SF. TDP1/TOP1 ratio as a promising indicator for the response of small cell lung cancer to topotecan. J Cancer Sci Ther. 2014;6:258-67.

83. Das SK, Rehman I, Ghosh A, Sengupta S, Majumdar P, Jana B, Das BB. Poly(ADP-ribose) polymers regulate DNA topoisomerase I (Top1) nuclear dynamics and camptothecin sensitivity in living cells. Nucleic Acids Res. 2016;44:8363-75.

84. Zeng Z, Cortés-Ledesma F, El Khamisy SF, Caldecott KW. TDP2/TTRAP is the major 5'-tyrosyl DNA phosphodiesterase activity in vertebrate cells and is critical for cellular resistance to topoisomerase IIinduced DNA damage. J Biol Chem. 2011;286: 403-9.

85. Gómez-Herreros F, Romero-Granados R, Zeng Z, Alvarez-Quilón A, Quintero C, Ju L, Umans L, Vermeire L, Huylebroeck S, Caldecott KW, CortésLedesma F. TDP2-dependent non-homologous endjoining protects against topoisomerase II-induced DNA breaks and genome instability in cells and in vivo. PLoS Genet. 2013;9:e1003226. 